\title{
NERVE GRAFTING AND NERVE SUTURE IN POSTOPERATIVE FACIAL PALSIES. A REPORT OF 69 CASES
}

\author{
KARSTEN KeTTEI *
}

Facial palsy is serious not because it endangers the patient directly but because the face being "the mirror of the soul" the afflicted patient loses what Duel ${ }^{17}$ so aptly named "the language of facial expression". That this may have far reaching psychic, social and economic consequences needs no explanation.

To give back to the patients the power of mimicry is the goal of our therapy. The symmetry and synchronism of the emotional movements of the face is dependent on the close co-operation of the cortical facial centres of both hemispheres, and the only was to re-establish this cortical interplay in cases of peripheral facial palsy is to repair the injured nerve at the site of the lesion.

$\mathrm{Ney}^{34}$ in 1922 published a method of infratemporal repair as worked out on the cadaver. Bunnell ${ }^{12}$ in 1925 was the first to perform a successful intratemporal suture of the nerve (published 1927), followed by Mar$\operatorname{tin}^{29}$ (1931).

Chief credit for the enormous advances in this field is due to Ballance and Duel ${ }^{2}$ (1932) and numerous reports of successful operations from all over the world are now available, among others by Bauer ${ }^{3} \mathrm{Bchr}$ man ${ }^{4}$, Bergström ${ }^{5}$, Bloch, Bourgeois, Aboulker and Lefèvre ${ }^{7}$, Bunnell and Boyes ${ }^{13}$, Farrior and Caldwell ${ }^{19}$, Findlay ${ }^{20}$, Duel and Tickle ${ }^{18}$, Tickle ${ }^{38}$, Lindsay ${ }^{27}$, Brooke ${ }^{8}$, Kisch ${ }^{25}$, McArthur ${ }^{32}$, Martin ${ }^{29}$, Morris ${ }^{33}$, Fowler ${ }^{23}$, Flodgren ${ }^{21}$. The work of Sullivan ${ }^{37}$ (Toronto) and Lathrop ${ }^{26}$ (Boston) and of Cawthorne ${ }^{15}$ and Collier ${ }^{16}$ (London) ought to be mentioned as the most oustanding.

Thanks to a close co-operation with collegues in the Scandinavian countries I have since 1939 operated upon 260 patients according to Ballance and Duel ${ }^{2}$ and Bunnell ${ }^{12}$; among these 69 were due to a surgical lesion of the facial nerve of such a grade that a nerve graft or a nerve suture was needed. Preliminary reports of this part of my work have

Relatório apresentado ao X1X Congresso Internacional de Oto-Neuro-Oftalmologia, reunido em São Paulo em 11-17 de junho de 1954, subordinado ao $2^{\circ}$ tema oficial: Fisiopatologia do nervo facial.

* Chief-Surgeon, Frederiksborg County Hospital, Hillerod, Denmark. 
been read in Stockholm (1947) and London (1949). Two patients have been operated on lately and it has been impossible to trace one. The rest have all been re-examined by me.

\section{INDICATIONS FOR OPERATION}

Traumatic facial paralysis may result from mishap in otological surgery. 'Ihanks to modern antibiotics, whicis have almost eliminated simple mastoidectomies, and to the better technique prevailing today, the number of postoperative otological palsies has been widely reduced but can hardly be completely avouded. Trauma to the facial nerve may also follow extirpation of tumors of the brain, of the parotid gland and the face, skull fractures and accidents of various art. "1t has definitely increased as a result of the nature of modern warfaie" (Lathrop ${ }^{26}$ ). 'The palsies may be divided into two groups according to the time of unset.

1) Hucial palsy arising in direct conjunction with surgery or accident - The continuity of the nerve is not necessarily broken, and the palsy may in otological surgery be due to a mere pressure on a denuded nerve, a specule of bone pressed into the sheath, tearing of the sheath or a haematoma. $A$ severance of the continuity should, however, be strongly suspected and only by exploration the nature of the lesion can be told.

Previously I have re-examined 169 cases of otitic palsies, conservatively treated regarding the nerve. In 111 cases the palsy was noted directly after a simple or radical mastoidectomy and by re-examination 3-30 years later 60 per cent had a massive palsy. An analysis showed that if the nerve had been severed, function never returned spontaneously.

I quite agree with Sullivan 37 and Cawthorne 15 that if a complete facial palsy arises in direct conjunction with the operation the repair should be undertaken without delay. From experience I know how much easier it is to find the nerve stumps at once than months or years after, when they have to be isolated in granulations and scar tissue. Moreover, if immediately performed the muscles have had no time to degenerate.

Colier 16, however, is in favour of expectation. "Since a nerve graft may be necessary in these cases it may be urged that operation should be undertaken at once. 'lihere are, however, two good reasons for delay. In the first place infection in the neighbourhood of a graft or suture leads to fibrosis, both intra and extraneural, which prevents the regenerating axons reaching the peripheral stump. second, the outgrowth of Schwann cells from the peripheral stump towards the center, which plays the part of a bridge by which the regenerating axons reach the periphery, is most vigorous between 15 to 25 days after division. Delay, therefore, for about three "weeks will favor satisfactory regeneration".

Bloch, Burgeois, Aboulker and Lefèvre 7 agree with Collier's point of view. Miss Collier 16 may be perfectly right; however, my experience has told me that by local and general administration of antibiotics a present infection is no contraindication for immediate repair of the nerve. Many of the otological injuries occur after a radical mastoidectomy performed in a chronic otitis and, as pointed out by sullivan $3 \overline{7}$, we are here dealing with a low grade infection.

How long time after the lesion of the facial nerve can a direct repair be tried? a) If the site of lesion is surgically accessible, which in practice means distal to the geniculate ganglion, and if no degeneration of the muscles has taken place, indicated by a strong response to the galvanic current, the repair is justified 
at any time. b) If the site of lesion is inaccessible but the muscles have not degenerated an anastomosis between the facial nerve and one of the cranial nerves (hypoglossus, glossopharyngeus and especially the spinal accessory nerve 28 ) should be tried; the result may be a face which looks normal when at rest, and voluntary movements can be performed but mimicry will never return. c) If the muscles have degenerated any attempt to repair the facial nerve is contraindicated, and plastic operations should be resorted to, as described among others by Brown 9, Brown, McDowell and Fryer 10, Adams 1, Brunner 11, Blair 6 , Brown 9, Owens ${ }^{35}$ and Fogh-Andersen 22 .

2) Hacial palsy occurring after an interial of freedom - Here we know that the continuity is unbroken, and the palsy may be due to pressure of tampronade, to oedema or to haemorrhagia in the facial canal. The prognosis is on the whole good. The palsy may also be due to a progrediating osteitis, which indicates a revision. Decompression should only be considered after a careful observation for at least 2 months.

\section{TECHNIQUE}

Excellent descriptions have been published by Lathrop 26, Sullivan ${ }^{3 i}$, Bunnell 12 and Maxwell 30 ; only a few points shall be stressed here.

Nerve graft - The prognosis varies according to the site of the nerve graft, best results being obtained in the first two of the following groups: a) intratemporal grafts: here the whole graft is situated within the Fallopian canal between the geniculate ganglion and the stylomastoid foramen; b) intra + extratemporal grafts, where the proximal end is lying in the Fallopian canal, the distal end connected with the facial nerve stump in the soft tissues; c) extratemporal grafts, in which the whole graft is placed outside the stylomastoid foramen.

As a suitable graft I have for years used the ilioinguinal nerve as suggested by Bergström 5, because it is easy to find and of the right calibre. Bunnell and Boyes 13 have suggested the use of "cable-grafts" instead of a single graft of a bigger calibre, maintaning that the latter is more inclined to necrotize as compared with several grafts of less calibre. Personally I prefer a single graft, the distal end of which, if necessary, in extratemporal repair, can be split and sutured to the distal nerve stumps after the division at the pes anserinus. In this way excellent results have been obtained by Maxwell 30 and Lathrop 26. Cardwell 14 reported a case where the facial nerve was sacrificed in removing a tumor of the parotid gland: 3 grafts of $60 \mathrm{~mm}$. were sutured to the proximal end of the facial nerve and their free end implanted directly in the facial muscles with ensuing good result.

A perfect coaptation between graft and nerve stumps is all important and should be undertaken under magnification. Sullivan 37 recommends the use of a degenerated graft, maintaining that it is easier to coapt.

It the distal end of the graft must be united to the peripheral facial stump outside the stylomastoid foramen, this is best done by means of Sullivan's plasma glue method. If sutures are used, they should be placed in the nerve sheath only, not through the nerve as this will produce intraneural scar formation, which is a hindrance to the gowngrowth of the neurofibrils.

Nerve suture - In very few cases will it be possible to perform a direct intratemporal suture of the nerve. By Bunnell's "re-routing" method 12 the course of the facial nerve may be shortened by lifting it out of the Fallopian canal and suture the stumps directly across the promontory (fig. 1). 

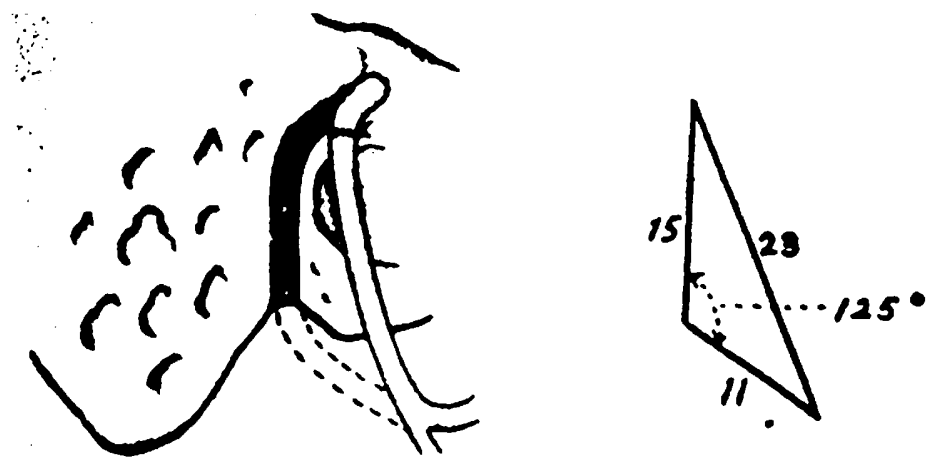

Fig. 1 - Re-routing of the facial nerve according to Bunnell.

Most authors, among whom Cawthorne 15 and Sullivan 37 , prefer a graft to a suture after "re-routing" the nerve, because it leaves the nerve in the Fallopian canal with an undisturbed blood supply, and even if the results which I have obtained by following Bunnell's intentions are satisfactory, the results of nerve grafting are so good, that I too prefer this method.

Bunnell 12 is of course quite right that by direct suture the neurofibrils will only have to pass one hindrance, but from practice we know that if only the coaptation is good, excellent results can be expected from nerve grafting and it should be remembered that if one has to sacrifice important structures (the middle ear) which can be avoided by using a graft, in order to perform a re-routing, this operation is of course strongly contraindicated.

The after-treatment is of the greatest importance. The muscles must be supported while the nerve is recovering. Various hooks and splints have been recommended, but I quite agree with Sullivan 3 i that any fascia lata hook-up operation should be avoided during the stage of recovery. Massage and galvanism are of the greatest importance and as soon as reinnervation starts, active movements besore a mirror should be instituted.

\section{RESULTS}

It must be born in mind that not even the most successful operation will be able to restore function completely. The results, however, may be extremely satisfactory, and they ought to be judged not by how much function falls short of 100 per cent, but by what has been achieved compared with the condition that would have been present without surgical in!ervention.

The results may be divided into two groups, according to the condition of the muscles at the time of repair and to the proceeding of the operation.

A) Cases in which no degeneration of the muscles had taken place and in which the operation was successfully performed - Only when these conditions are fulfilled, good results can be expected. To this group 52 cases belong (table 1). 
Examples of the results obtained are illustrated in figures 2 to 40 . A clinically satisfactory result consequently was obtained in 47 cases ica. 90 per cent), insufficient re-innervation was noted in 4 cases (ca. 8 per (ent), while in one patient no re-innervation at all took place.

Foul of these patients (31-42-51 and 7 years of age) were referred to me 17 days, $1 \frac{1}{2}, 7$ and 10 months respectively after the nerve had been cut during a simple mastoidectomy, a labyrinthectomy ( 2 cases) and a fenestration, and a nerve graft, $10-20 \mathrm{~mm}$. in length was inserted with perfect healing. I am unable to explain the one complete and the 3 partial failures. Perhaps the coaptation was bad as these operations were done before I started using magnification.

In the last case I operated on a patient on the diagnosis of Bell's palsy but found a sarcoma on the descending part of the facial nerve, as previously described. It was removed and a graft inserted. Ten months later movements returned but the end result is clinically unsatisfactory. The patient was treated by X-rays postoperatively, which may have damaged the neurofibrils and the graft.

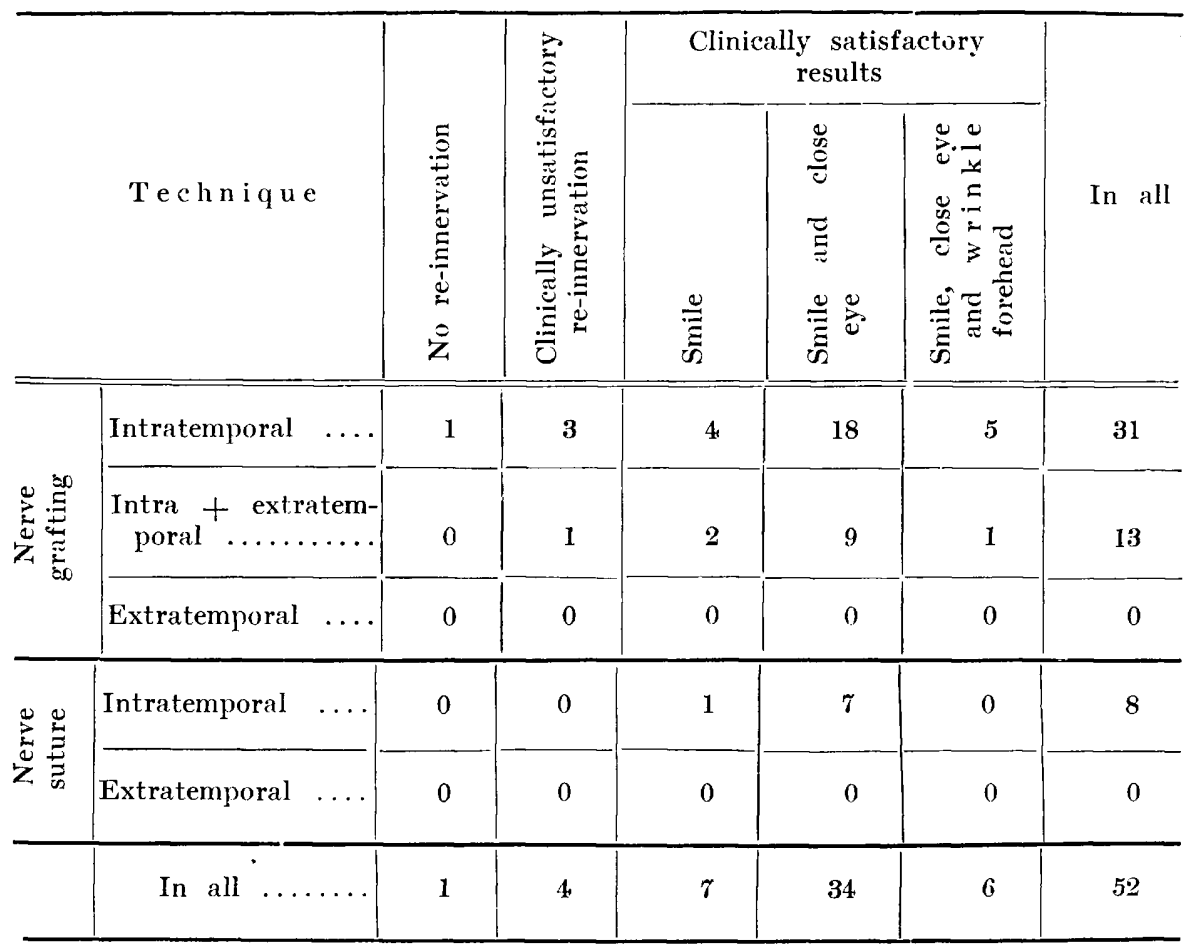

Table 1 - A total number of 52 cases, in which the conditions for and the proceeding of the repair were satisfactory, were operated on. No re-innervation: 1 case (ca. 2\%). Insufficient re-innervation (clinically unsatisfactory result): 4 cases (ca. $8 \%$ ). Clinically satisfatory result: 47 cases (ca. 90\%). 
B) Cases in which the muscles had degenerated partially at the time of repair or to me insurmountable technical difficulties were encountered To this group 14 patients belong. All the patients had of course been told in advance that in their cases the operation had to regarded as an experiment and that the final issue could not be foretold (table 2). In 5 cases partial degeneration of the muscles had taken place, and in 4 cases the palsy was due to a simple or a radical mastoidectomy, in one case to the removal of a tumor of the parotid gland.

The patients were admitted to the hospital half till several years after the first operation with a complete palsy, 2 of them with a great retroauricular fistula, the closure of which they insisted upon. In these cases there was everything to gain, nothing to lose. In 2 cases the result was completely negative, in 3 the muscles were re-innervated but clinically unsatisfactorily.

The technical difficulties, to me insurmountable, applies especially to extratemporal repairs, where the paisy was due to removal of a retromandibular tumor, a tumor of the parotid gland, to the incision of an abscess at the angle of the mandible, many years before, or to a gunshot lesion. In these cases the bed consisted of scar tissue, where only minor strands of the distal end of the facial nerve could be found. Moreover, thanks to a long interval between damage and repair the response of the muscles to the galvanic current was in most cases reduced. It should,

\begin{tabular}{|c|c|c|c|}
\hline & Technique & No re-innervation & $\begin{array}{c}\text { Clinically } \\
\text { unsatisfactory }\end{array}$ \\
\hline & Intratemporal & 3 & 1 \\
\hline 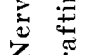 & Intra + extratemporal & 1 & 0 \\
\hline & Extratemporal & 2 & 0 \\
\hline & Intratemporal & 0 & 0 \\
\hline$\stackrel{\breve{\Xi}}{\Xi}$ & Intra + extratemporal & 0 & 3 \\
\hline & Extratemporal & 0 & 4 \\
\hline & In all & 6 & 8 \\
\hline
\end{tabular}

Table 2 - Fourteen patients have been operated on, in whom either partial degeneration of the muscle at the time of repair had taken place $(5$ cases) or the technical dificulties were insurmountable to me $(9$ cases $)$. 
however, be remembered, that Maxwell ${ }^{30}$ and Lathrop ${ }^{26}$ have obtained excellent results in extratemporal repairs.

One case should be reported, because of the bad end-result:

A man, 24 years of age, was admitted to the hospital October 8th, 1945 . In 1927 he was admitted to another clinic with a chronic otitis media and a preoperative facial palsy. Firstly a radical mastoidectomy was performed, one month later a labyrinthectomy, and two months later a revision was done. On admission in 1945 the palsy was hardly noted when the face was at rest, but he was unable to close the eye and wrinkle the forehead and could only move the corner of the mouth very little. The reaction to the galvanic current, however, was strong. In the radical, cavity pus and granulations were observed.

Because of the inability to move sufficiently the corresponding side of the face and the strong response to the galvanic current, an attempt was made to repair the nerve. 'The cavity was cleaned of granulations and the facial nerve was isolated at the stylomastoid foramen. Up till the bend of the lateral (removed) semicircular canal it looked normal, but the tympanic (horizontal) part was extremely thin and could only be followed iill near the geniculate ganglion; there it disappeared. In spite of great care I must have damaged this tiny strand, and as all anatomical landmarks on account of previous operations were missing 1 was unable to locate the proximal end of the nerve. A graft was placed proximally at the supposed site of the geniculate ganglion and connected 'with the peripheral stump of the facial nerve. Complete palsy followed and movements did not return. I have learned that later on anastomosis operation and plastic operations have been tried.

In this cases severe damage to the patient has been done. On arrival his face looked normal even if he could only move the afflicted side of the face very little. My efforts to improve the condition resulted not only in a complete failure but a pronounced impairment.

I have earlier (1943) stated ${ }^{24 d}$ as follows: "If only the slightest connection remains between the proximal and the distal part of the nerve, this suffices to keep the oral muscles at a degree of tone that enables the angle of the mouth on the defective side to be on about the same level as the angle on the unaffected side". I have been able to confirm this statement on several occasions later, where my endeavours to improve the condition fortunately were successful. Lately McGillicuddy ${ }^{31}$ has arrived at the same conclusion based on a rase of 20 years duration.

However, if in a case of facial palsy with normal appearance of the face, but with no or very little ability to move the affected side of the face, but a strong response to the galvanic current, a tiny atrophic strand is found at the site of lesion, I should not hesitate to resect this and insert a graft provided a clean cut of a normal looking nerve proximal ond distal to the atrophic strand can be secured.

The interval between damage and repair has varied widely: 8 repairs were done within 48 hours, 8 within one week, 6 within 2 weeds, 17 between 1 and 3 months, 10 between 3 and 12 months, 12 between 1 and 2 years. 2 between 2 and 3 years, and 6 more than 3 years after onset. 
A repair should, as already mentioned, be tried at any time provided the muscles have been kept alive as indicated by a strong response to the galvanic current, and provided the site of lesion is surgically accessible, which in practice means distal to the geniculate ganglion. It ought to be remembered that Tickle ${ }^{38}$, in a case of necrosis of the labyrinth, obtained an excellent result by uniting the proximal end of the facial nerve, just where it pierces the dura, to the distal stump by means of a $16 \mathrm{~mm}$. graft.

Figure 35 illustrates that good results may be obtained even if a comparable long time has elapsed since the injury. The operation, however, is much more difficult at this late stage (this repair was done $11 / 2$ years after the injury).

The length of the graft has varied from 4 to $50 \mathrm{~mm}$.: In 5 cases the graft measured up till $5 \mathrm{~mm}$.; in 14,6-10 mm.; in $21,11.20 \mathrm{~mm}$.; in 12 , $21.30 \mathrm{~mm}$; in $7,31.40 \mathrm{~mm}$; and in $2,41-50 \mathrm{~mm}$.

That good results may be obtained by means of short as well as long grafts is illustrated by figures $7-20$ and $30-32$.

The time when the first signs of returning mobility were noted was only remembered exactly by 30 patients, and has varied from 4 to 24 months, an average being 10 months, regardless of whether nerve suture or nerve grafting was performed. With one exception the movements always started in the muscles at the mouth, being for months preceeded by a feeling of returning tonus.

The relation between the time of returning function and the length of the graft is illustrated in table 3 :

\begin{tabular}{c|c|l}
\hline Time of returning function & $\begin{array}{c}\text { Number of } \\
\text { cases }\end{array}$ & \multicolumn{1}{|c}{ Length of nerve graft (mm.) } \\
\hline 4 & 3 & $20-21-25$ \\
5 & 5 & $5-6-8-10-25$ \\
$6-12$ & 13 & $4-5-10-10-14-1.4-15-15-20-25-30-35-42$ \\
$13-18$ & 6 & $20-28-35-35-35-40$ \\
$19-24$ & 3 & $20-32-50$ \\
\hline
\end{tabular}

From the figures above it can be seen that there is no direct relation between the length of the grat and the time when the first movements were noted.

Modern antibiotics have almost made simple mastoidectomies superfluous, and thus a major source of postoperative palsies has been eliminated. However, radical mastoidectomies are indicated in a great number of cases. 
To the list of sources may now be added fenestrations, and even if today a better technique is prevailing, damage to the facial nerve can hardly be completely avoided. To this may be added palsies due to extirpation of various tumors in the course of the facial nerve and to skull fractires and accidents of various art.

If, however, the repair is undertaken at once by a surgeon especially trained for this purpose, the patients have every chance of obtaining a clinically satisfactory result, if the site of lesion is surgically accessible.

\section{SUMMARY}

Since 1939, 260 patients with a peripheral facial palsy have been operated on by me according to Ballance and Duel, and in 61 cases nerve grafting, in 8 nerve suture was performed; 66 of the patients have been re-examined by me, 2 have been operated upon lately and one could not be traced.

If a complete facial palsy arises in direct conjunction with surgery or accident the repair should, if possible, be undertaken without delay; if it occurs after an interval of freedom and the continuity of the nerve is unbroken the prognosis on the whole is good. The technique is discussed and the importance of the after-treatment is stressed.

The results may be divided into two groups according to the conditions for and the proceeding of the repair, illustrated in tables 1 and 2. Among 52 cases, in which no degeneration of the musc'es had taken place and in which the operation was successfully performed a clinically satisfactory result was obtained in 47 patients. If these conditions are not fulfilled the prospect of a satisfactory result is a priori poor. It must be born in mind that not even the most successful operation will be able to restore function completely.

Fig. 2 - Intratemporal nerve grafting, $8 \mathrm{~mm}$., right side. Pictures taken $13 / 4$ years after the operation; steadily improving.

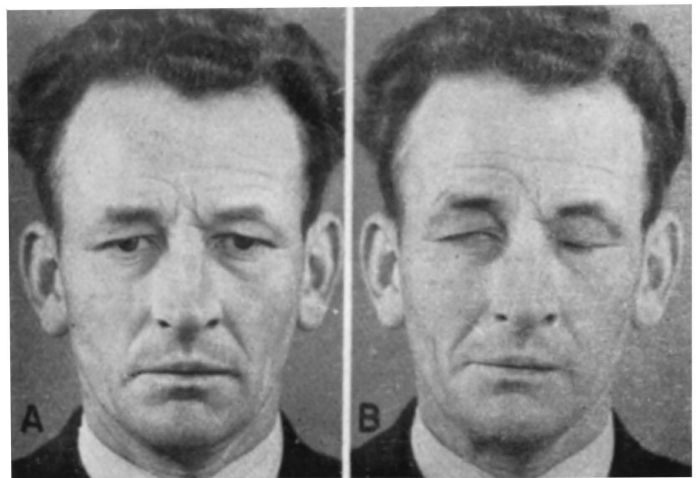



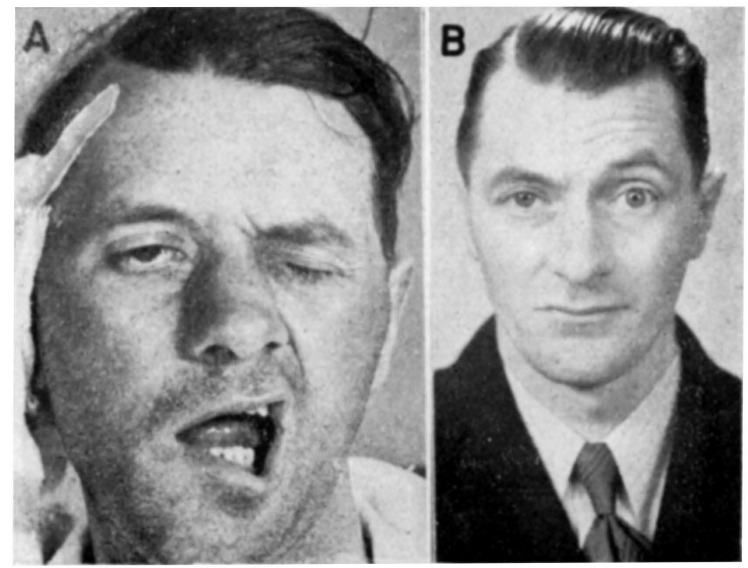

Fig. 3 -- Intratemporal nerve grafting, $10 \mathrm{~mm}$. At the side of lesion a tiny strand connected the nerve-stumps. At least $2 / 3$ of the nerve substance for $10 \mathrm{~mm}$. had been removed, and the gap bridged by cable-grafts, preserving the tiny strand. Before (A) and $31 / 2$ years after the operation (B).

Fig. 4 - Intratemporal nerve grafting, $4 \mathrm{~mm}$. Before (A) and I year after the operation; steadily improvincy.
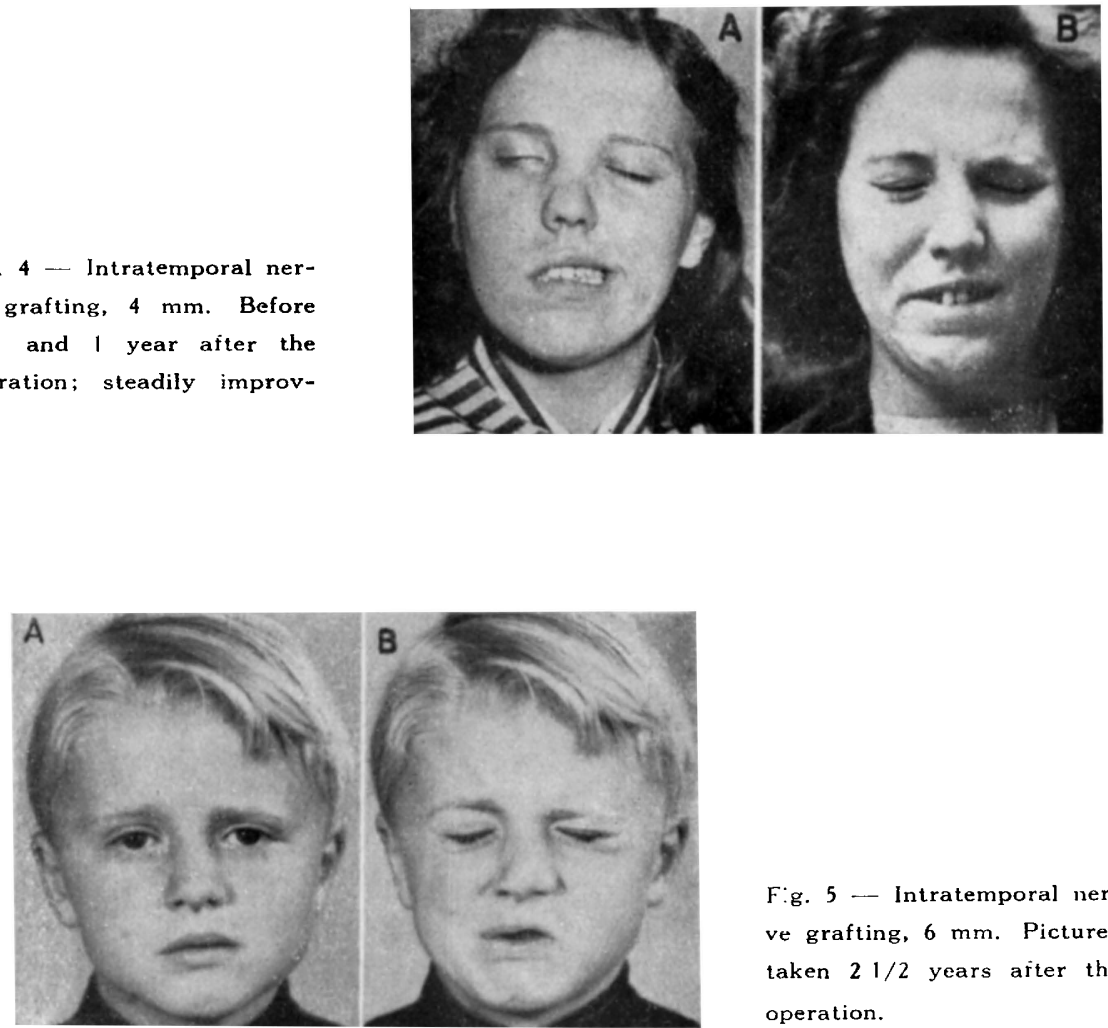

F:g. 5 - Intratemporal nerve grafting, $6 \mathrm{~mm}$. Pictures taken $21 / 2$ years arter theoperation. 

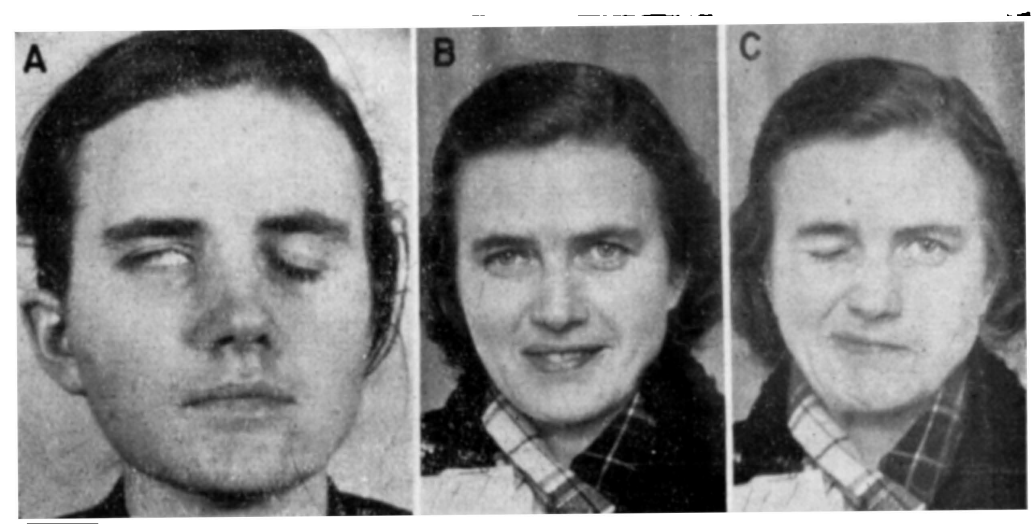

Fig. 6 - Intratemporal nerve grafting, $10 \mathrm{~mm}$. Before (A) and $23 / 4$ years after the operation $(B, C)$.
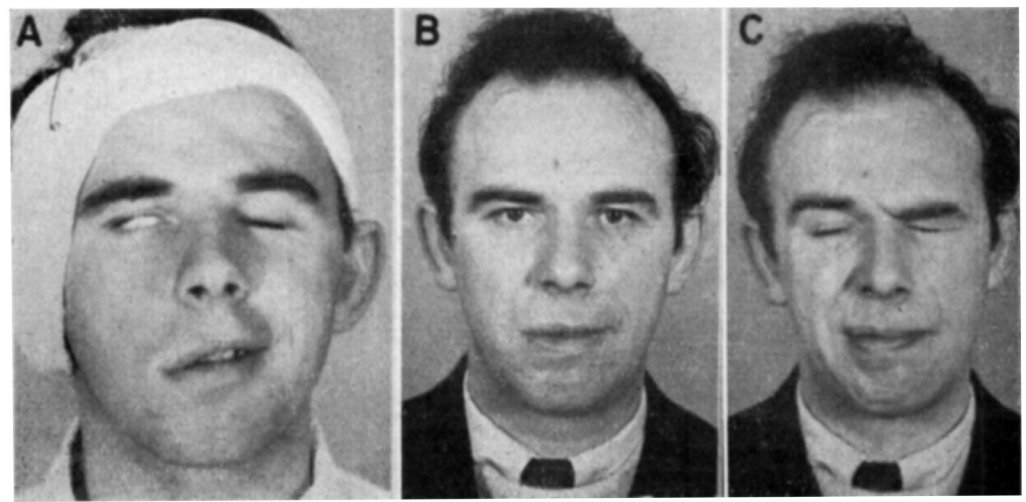

Fig, 7 - Intratemporal nerve grafting, $15 \mathrm{~mm}$. Before (A) and 4 years after the operation (B, C).
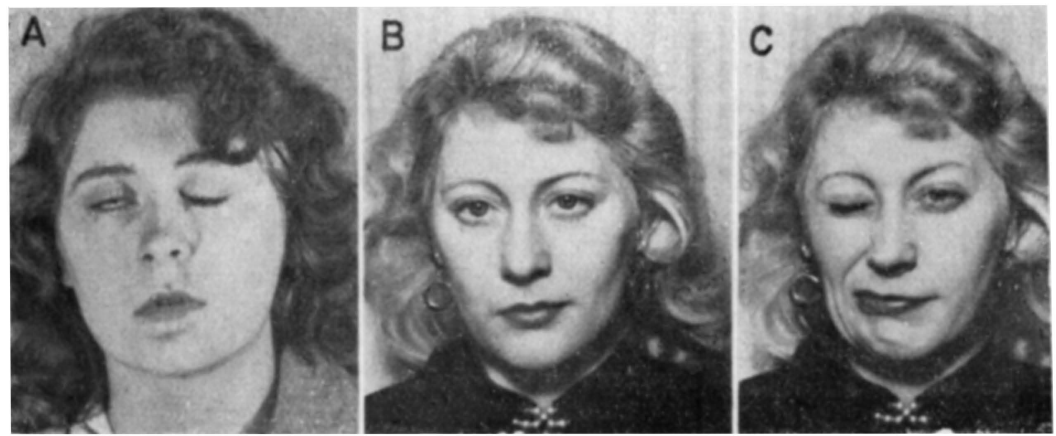

Fig. 8 - Intratemporal nerve grafting, $12 \mathrm{~mm}$. Before (A) and $43 / 4$ years after the operation $(B, C)$. 

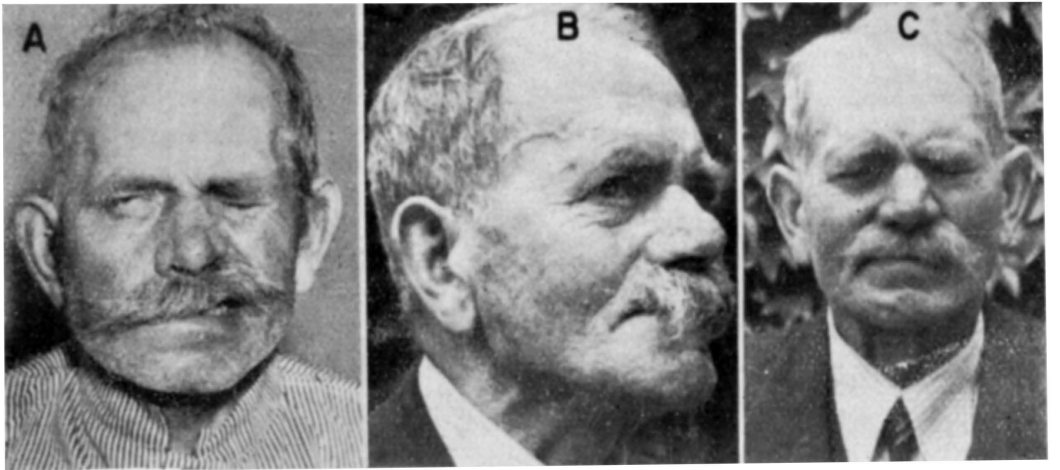

Fig. 9 - Intratemporal nerve grafting, $20 \mathrm{~mm}$. Before (A) and $11 / 4$ years after the operation (B, C).
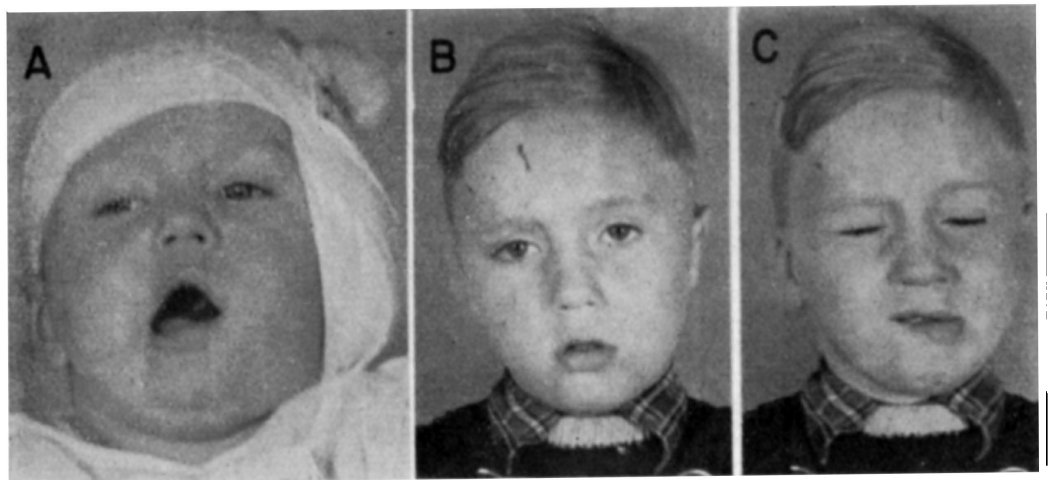

Fig. 10 - Intratemporal nerve grafting, $20 \mathrm{~mm}$., left side. Before (A) and ; years after the operation $(B, C)$.
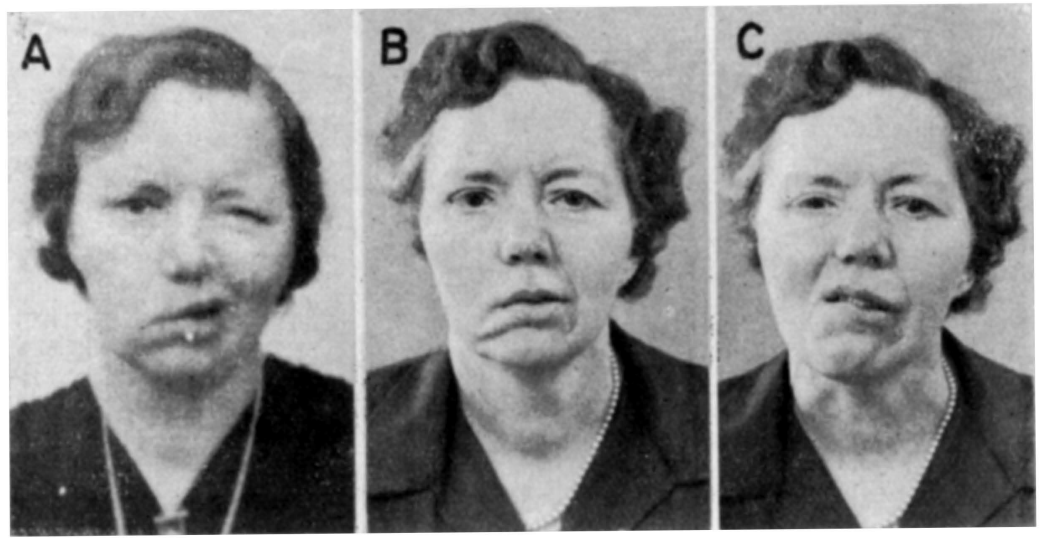

Fig. 11 - Intratemporal nerve grafting, $20 \mathrm{~mm}$. Before (A) and $61 / 4$ years after the operation $(B, C)$. 


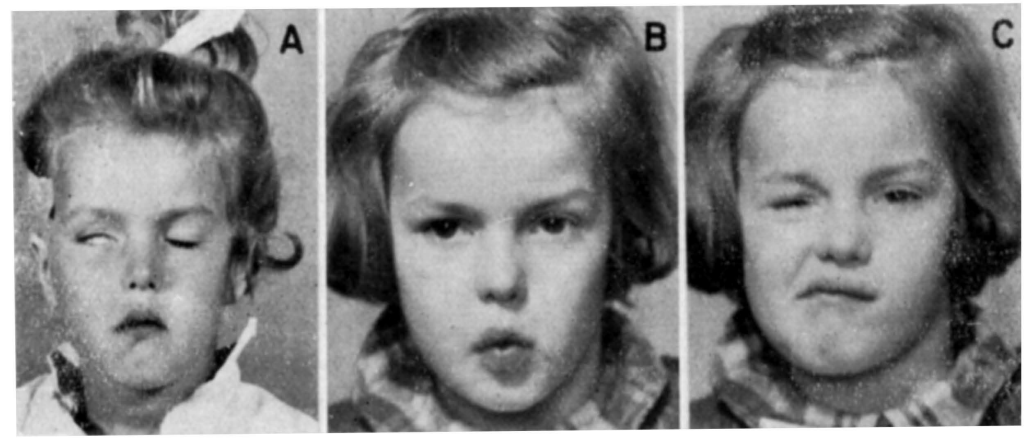

Fig. 12 - Intratemporal nerve grafting, $20 \mathrm{~mm}$. Before (A) and $11 / 2$ years after the operation; steadily improving $(B, C)$.

Fig. 13 - Intratemporal nerve grafting, $14 \mathrm{~mm}$., right side. Pictures taken $41 / 4$ years after the operation.
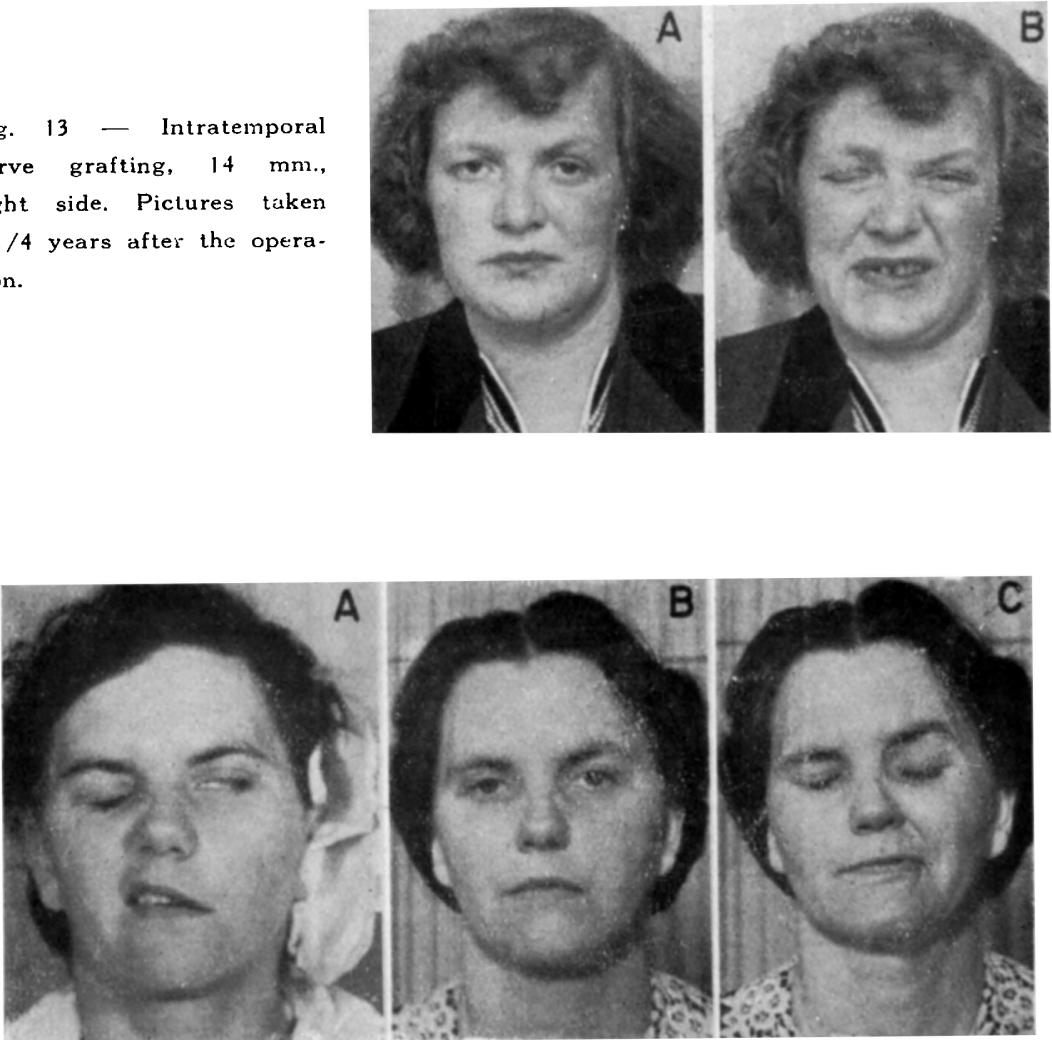

Fig. 14 - Intratemporal nerve grafting, $7 \mathrm{~mm}$. Before (A) and $23 / 4$ years after the operation (B, C). 

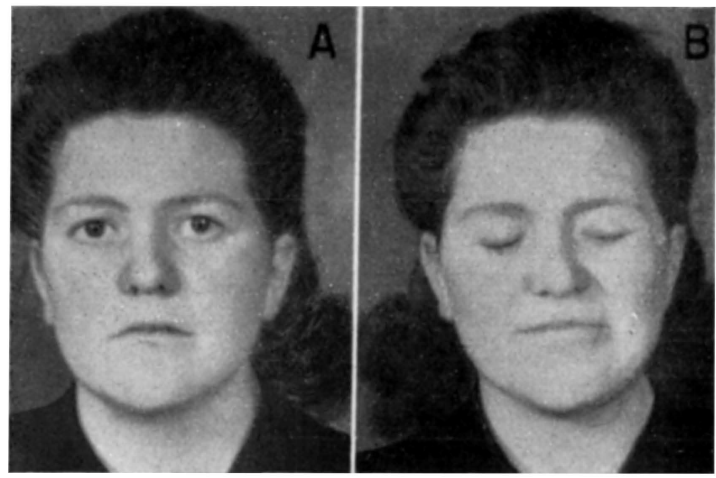

Fig. 15 - Intratemporal nerve grafting, $10 \mathrm{~mm}$., left side. Pictures taken i $1 / 2$ years after the operation, steadily improving at reexamination, but could not be traced later.
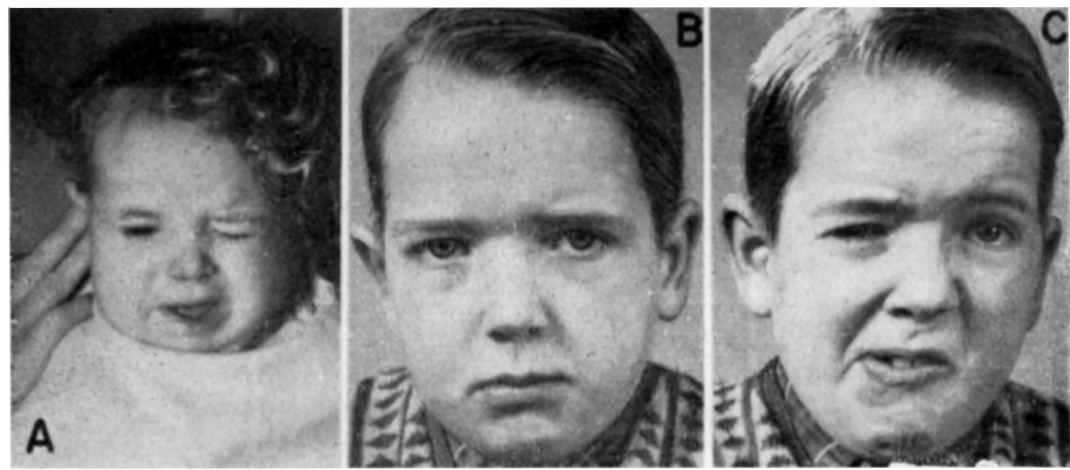

Fig. 16 - Intratemporal nerve grafting, $10 \mathrm{~mm}$. Before (A) and 7 years after the operation $(B, C)$.
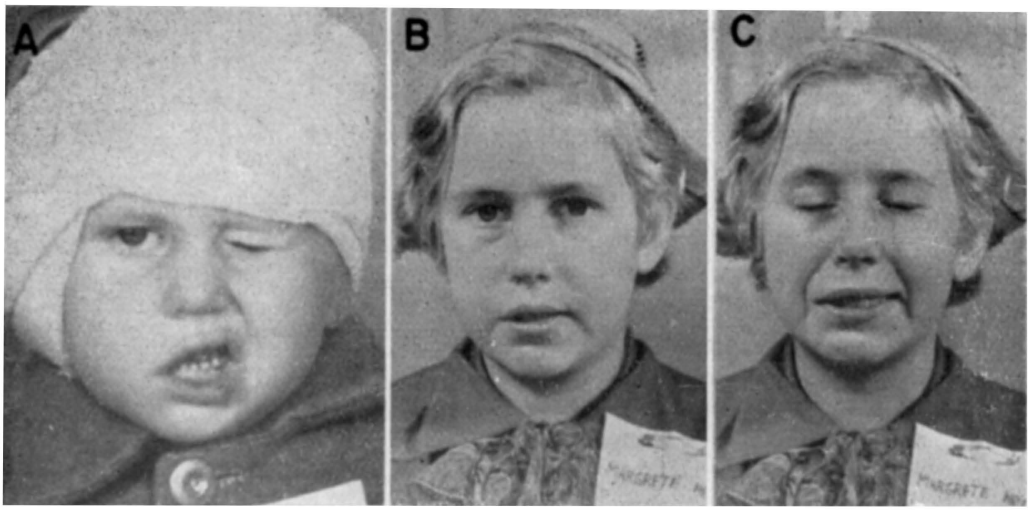

Fig. 17 - Intratemporal nerve grafting, $10 \mathrm{~mm}$., right side. Before (A) and $81 / 2$ years after the operation $(B, C)$. 

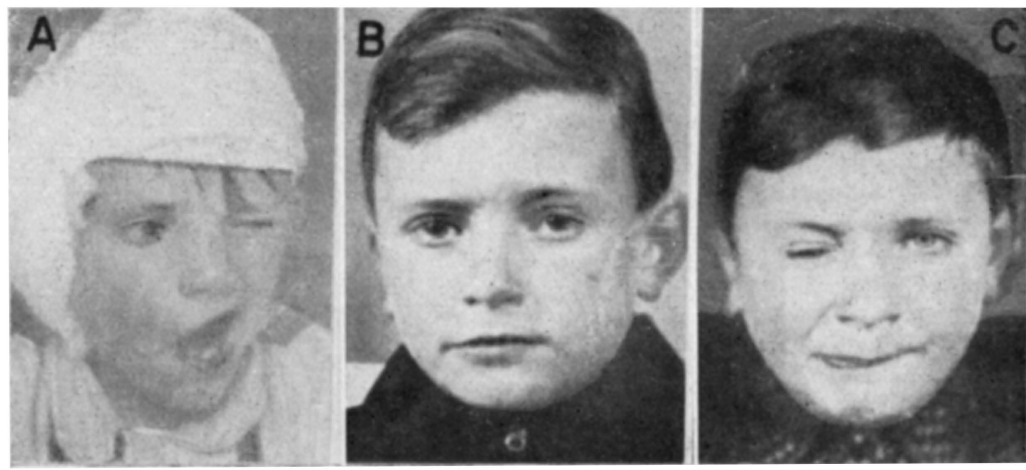

Fig. 18 - Intratemporal nerve grafting, $8 \mathrm{~mm}$. Before (A) and 2 years after the operation (B, C).
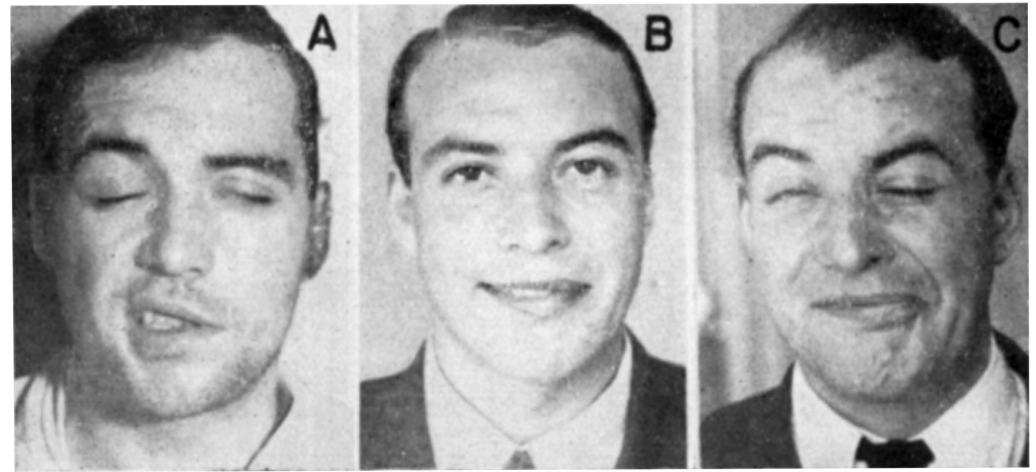

Fig. 19 - Intratemporal nerve grafting, $5 \mathrm{~mm}$ Before (A) and $11 / 2$ years after the operation (B, C).
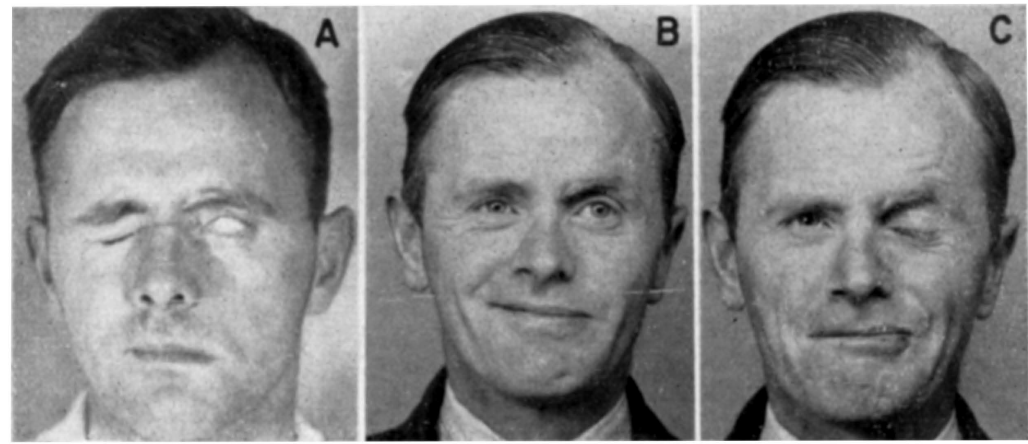

Fig. 20 - Intratemporal nerve grafting, $14 \mathrm{~mm}$. Before (A) and $3 / 4$ years after the operation $(B, C)$. Note function of all three branches. 


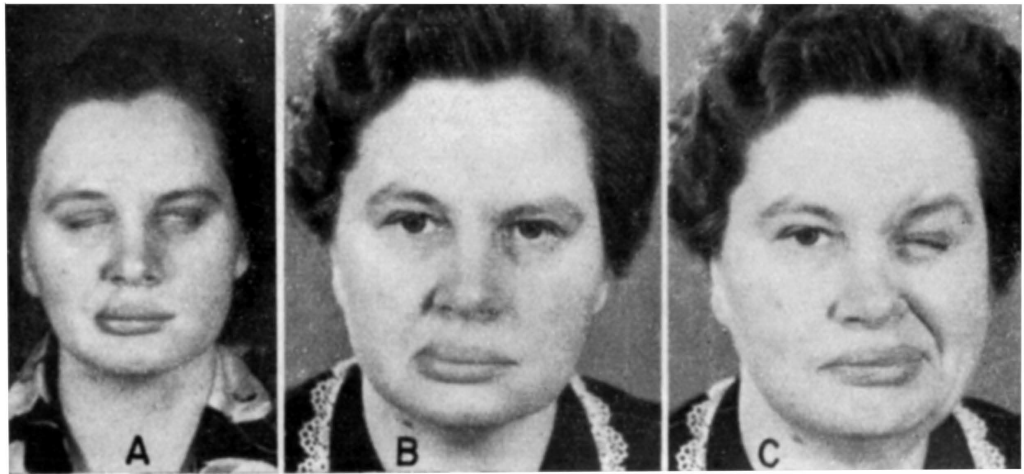

Fig. 21 - Intratemporal nerve grafting, $7 \mathrm{~mm}$. Before (A) and 9 years after the operation $(B, C)$.

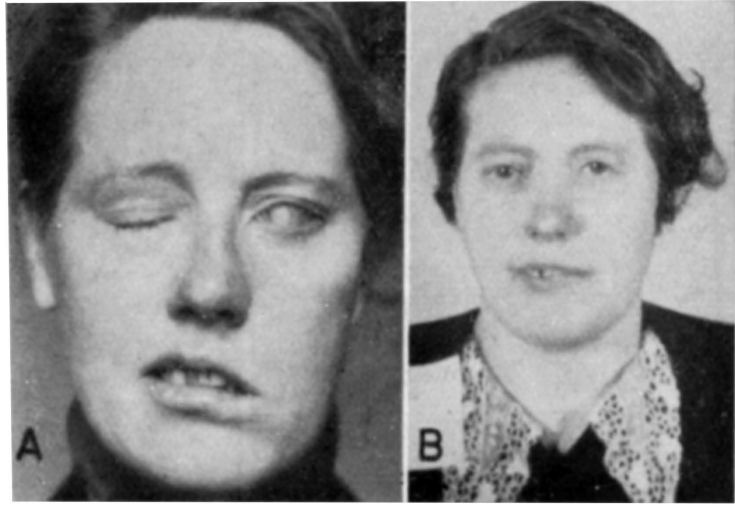

Fig. 22 - Intra + extratemporal nerve grafting, 35 mm., before (A) and $31 / 2$ years (B) after the operation. The result is clinically unsatisfactory, as she could rise the corner of the mouth only little, and was unable to close her eye and accordingly a partial tarsorhaphia had to be done.
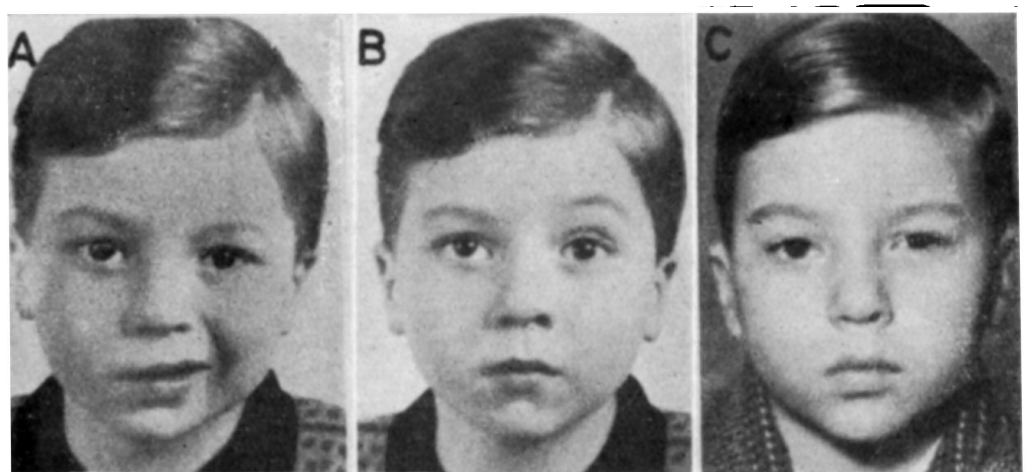

Fig. 23 - Intra + extratemporal nerve grafting, $32 \mathrm{~mm}$., right side. A tiny strand connected the proximal and distal nerve stump. This was preserved and an end-to-side graft was inserted substituting the missing part of the nerve. The result is poor. 

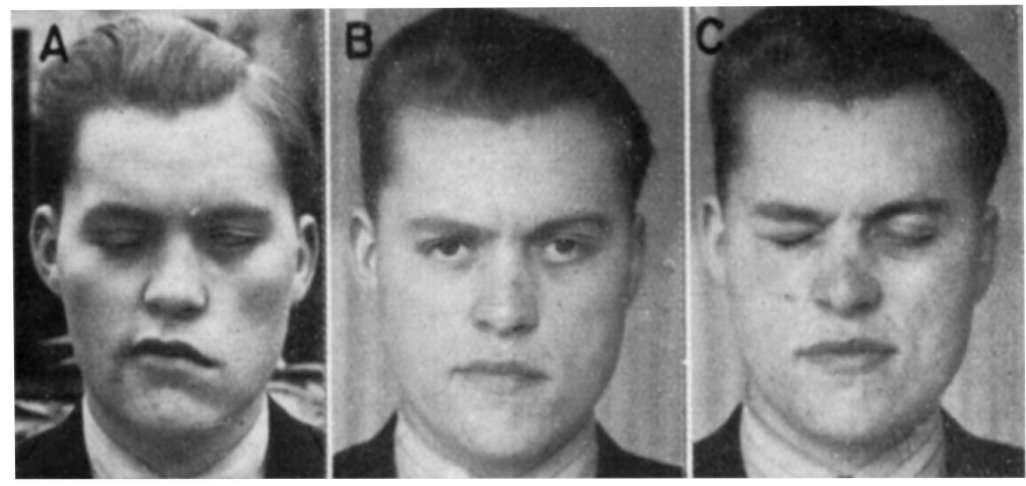

Fig. 24 - Intra + extratemporal nerve grafting. $35 \mathrm{~mm}$. Before (A) and $11 / 2$ years after the operation $(B, C)$.

Fig. 25 -- Intra + extra. temporal nerve grafting, 25 mni., right side. Pictures taken I year after the operation. At the site of lesion a tiny strand connected the proximal and distal nerve stump. This was preserved and the missing part of the nerve substituted by cable. grafts.
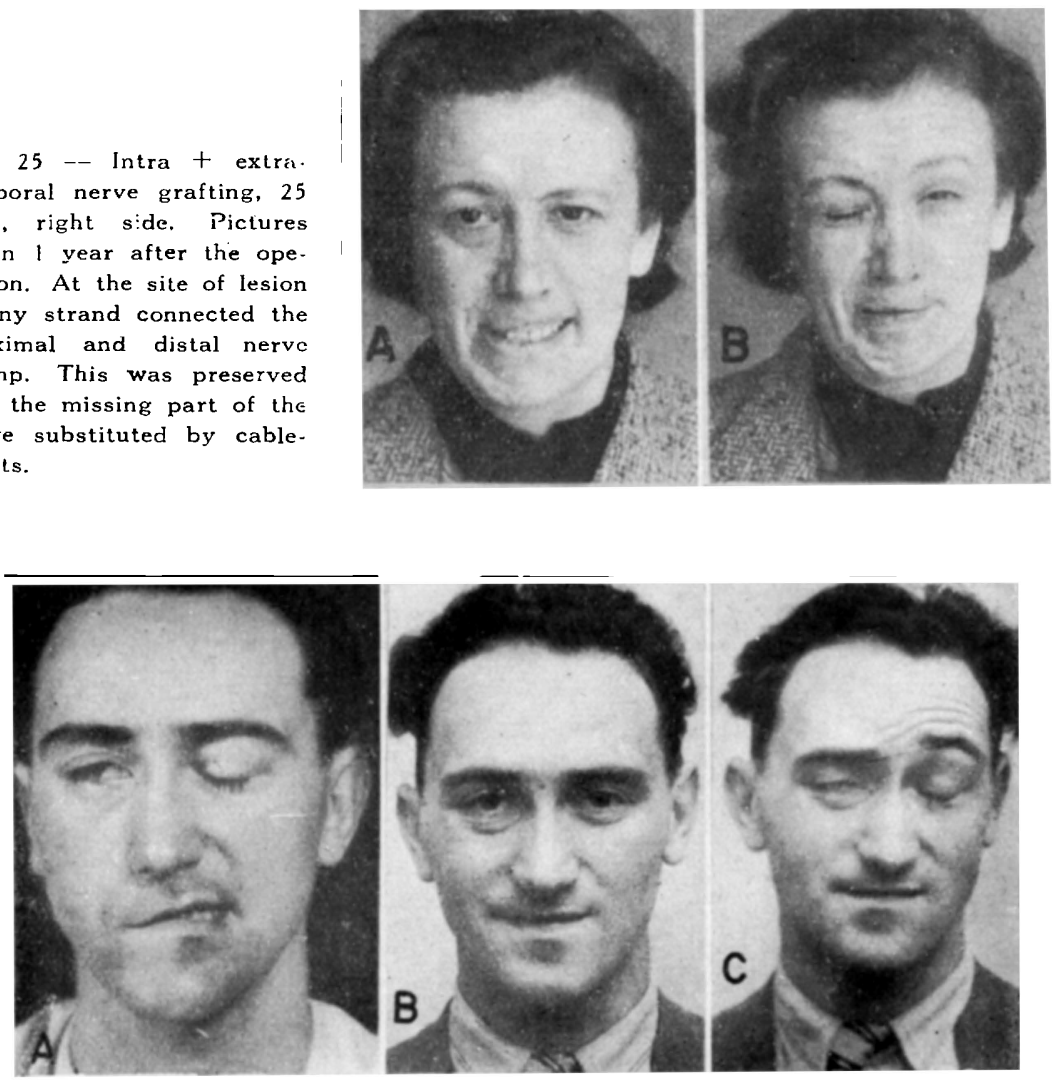

Fig. 26 - Intra + extratemporal nerve grafting, $25 \mathrm{~mm}$. Before (A) and $1 \mathrm{I} / 2$ years after the operation $(B, C)$; steadily improving. 

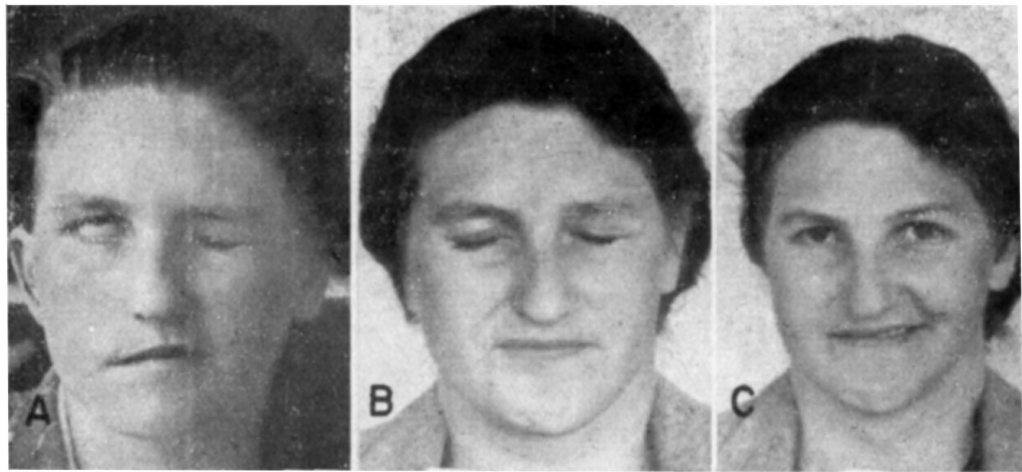

Fig. 27 - Intra + extratemporal nerve grafting, $25 \mathrm{~mm}$. Before (A) and 2 years after the operation $(B, C)$.
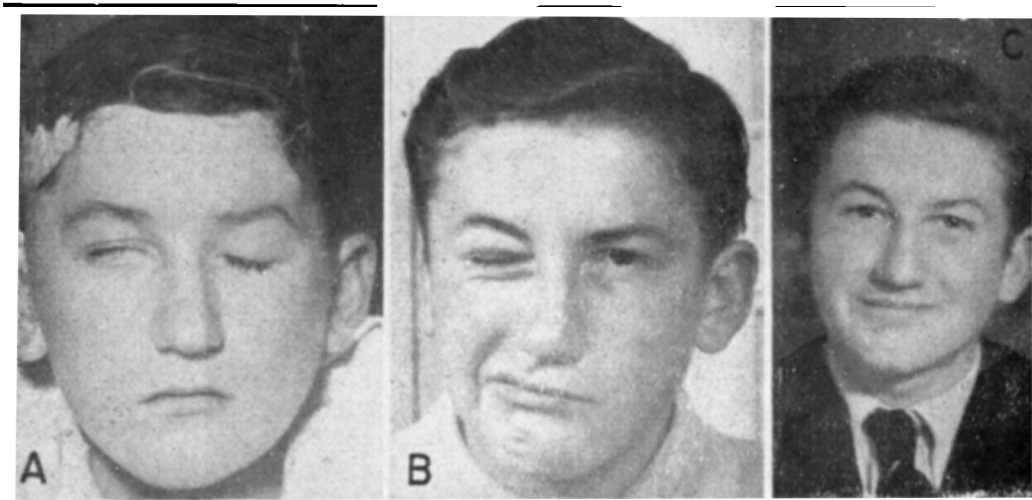

Fig. 28 - Intra + extratemporal nerve grafting, $35 \mathrm{~mm}$. Before (A) and 2 years after the operation $(B, C)$.
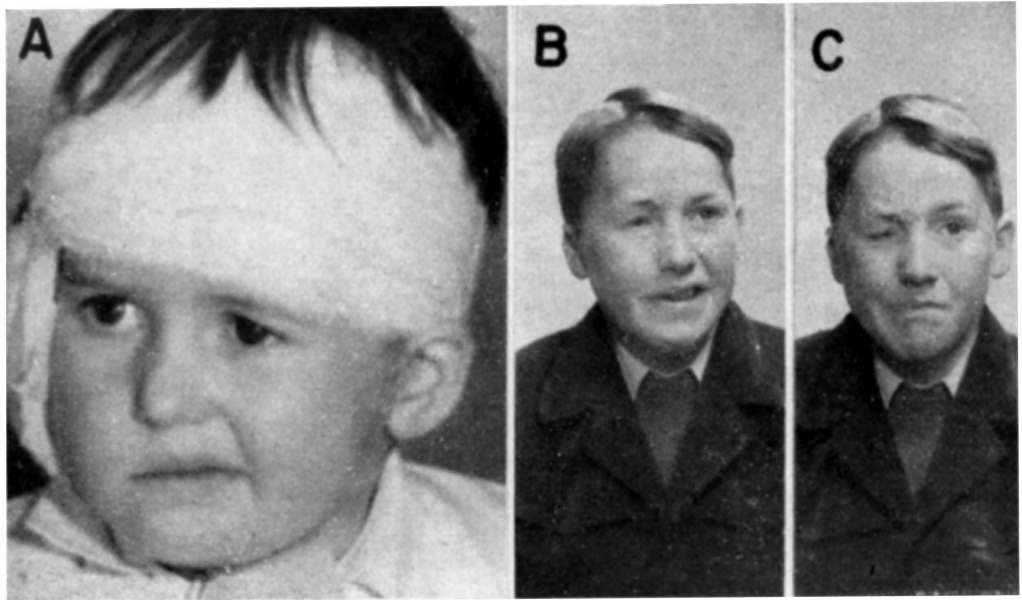

Fig. 29 - Intra + extratemporal nerve grafting, $20 \mathrm{~mm}$. Before and 7 years after the operation. 

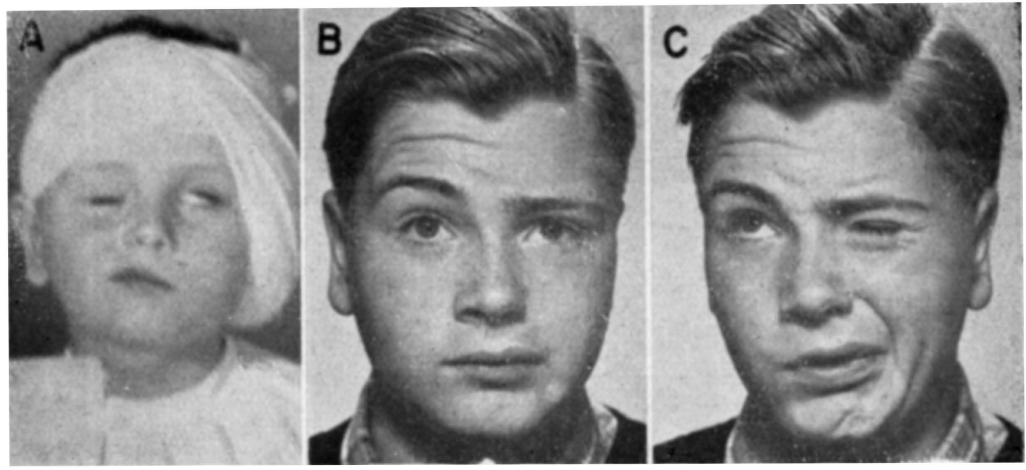

Fig. 30 - Intra + extratemporal nerve grafting, $35 \mathrm{~mm}$. Before (A) and $61 / 2$ years after the operation $(B, C)$.
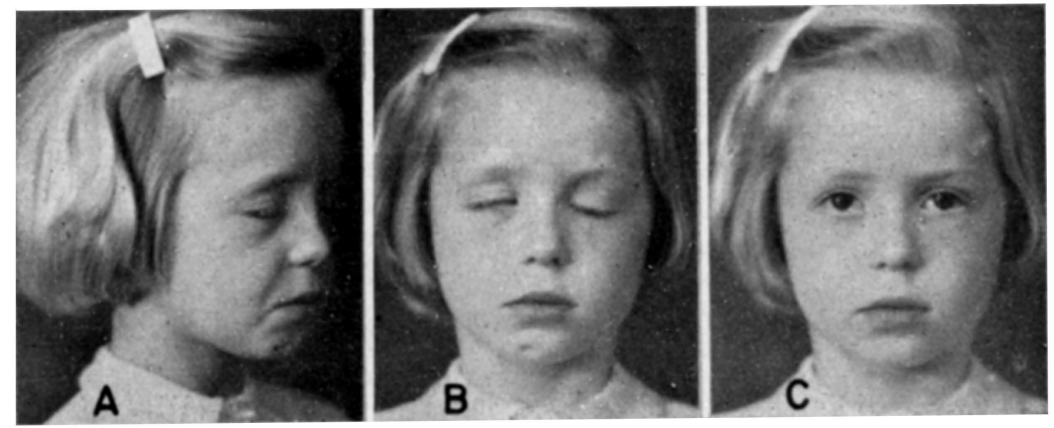

Fig. 31 - Intra + extratemporal nerve grafting, $15 \mathrm{~mm}$., right side. Pictures taken 5 years after operation.

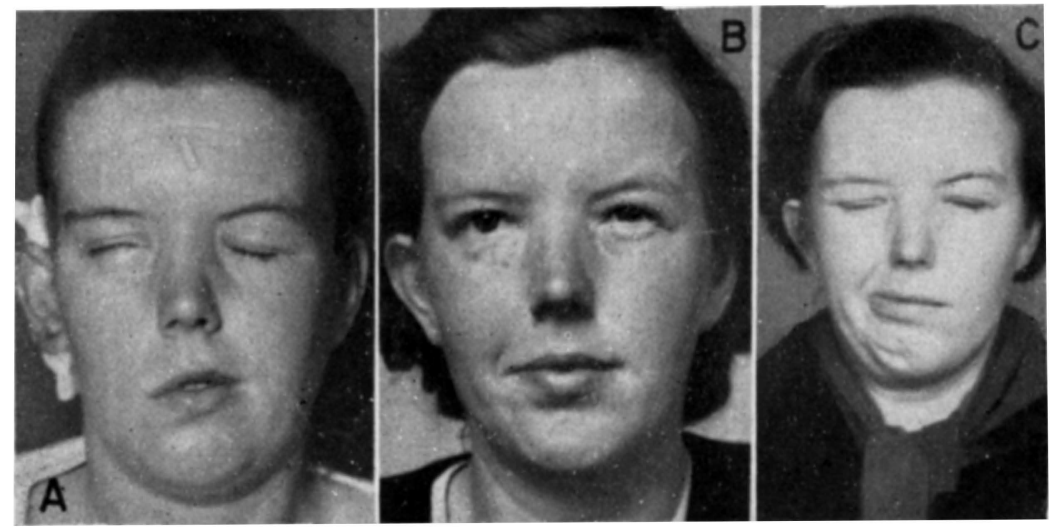

Fig. 32 - Intra + extratemporal nerve grafting, $42 \mathrm{~mm}$. Before (A) and 16 months after the operation $(B, C)$. 

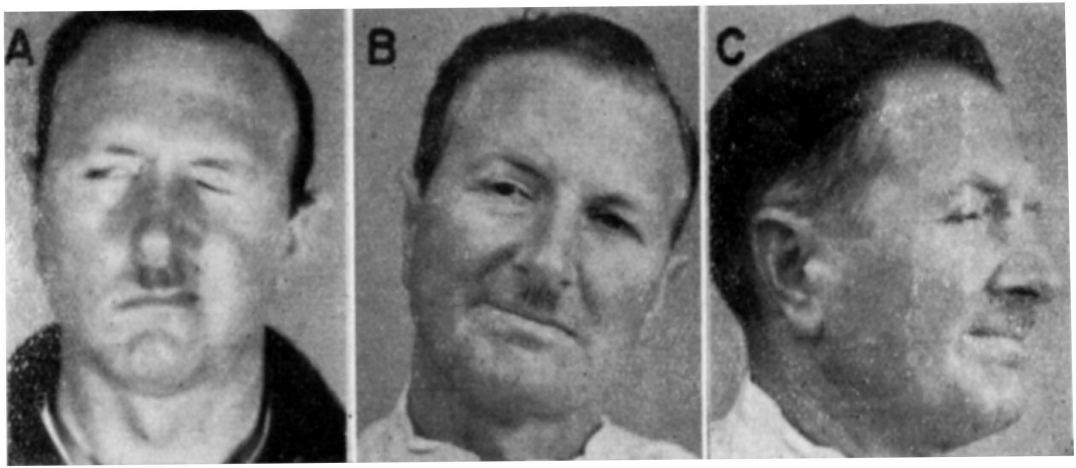

Fig. 33 - Intra + extratemporal nerve grafting, $30 \mathrm{~mm}$. Before (A) and 2 years after the operation $(B, C)$.
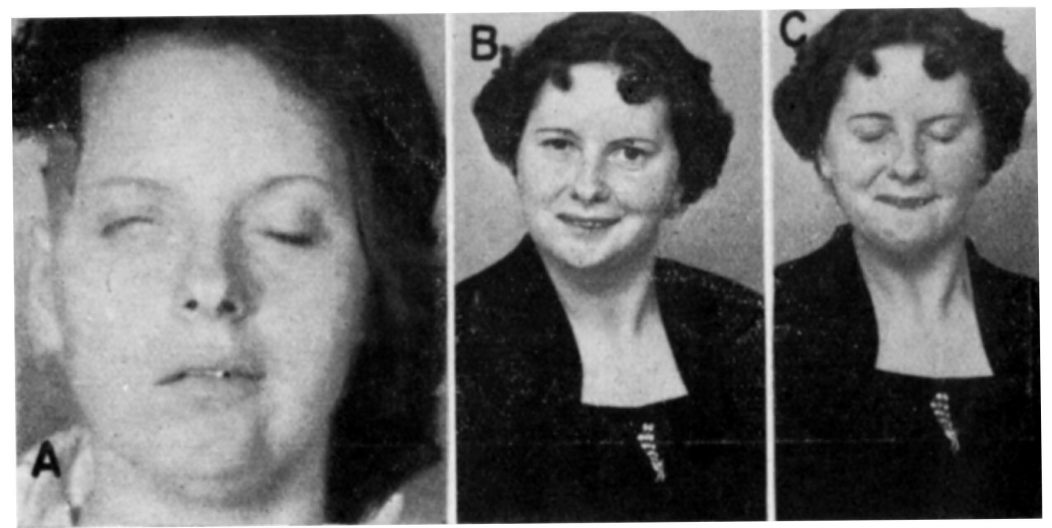

Fig. 34 -. Intra + extratemporal nerve grafting, $21 \mathrm{~mm}$, right side. Before (A) and 4 years after the operation (B, C).
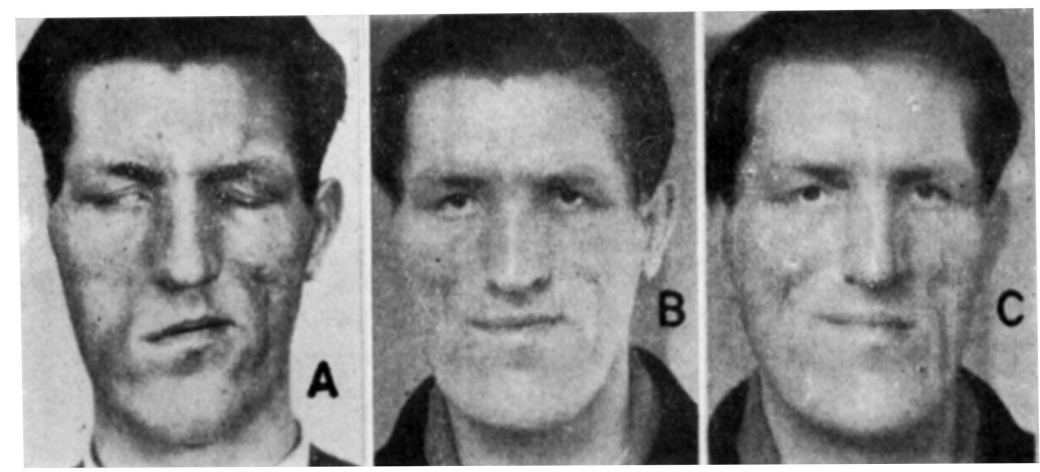

Fig. 35 - Nerve suture after re-routing the nerve according to Bunnell. Before (A) and 2 years after the operation (B, C). 

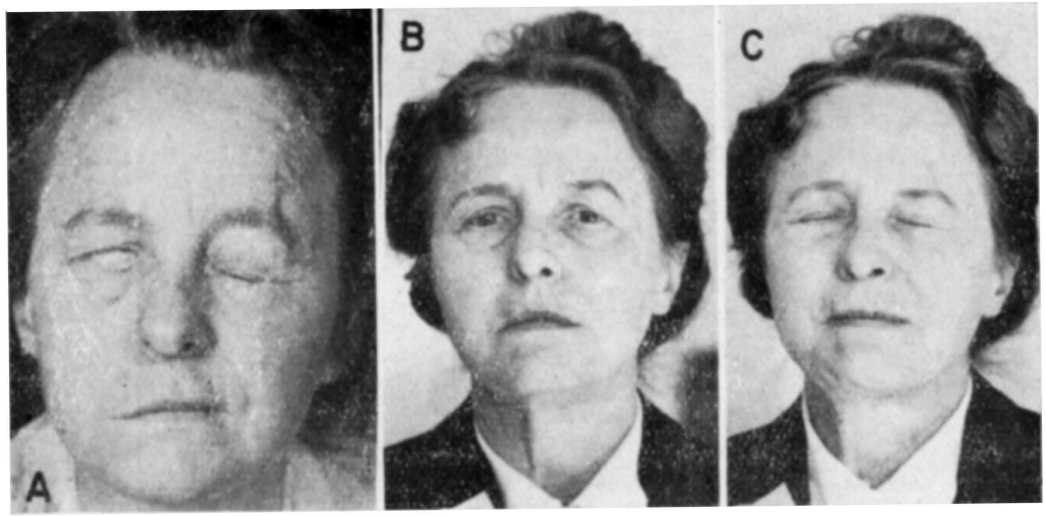

Fig. 36 - Nerve suture after re-routing the nerve according to Bunnell. Before (A) and 21/4 years after the operation (B, C).

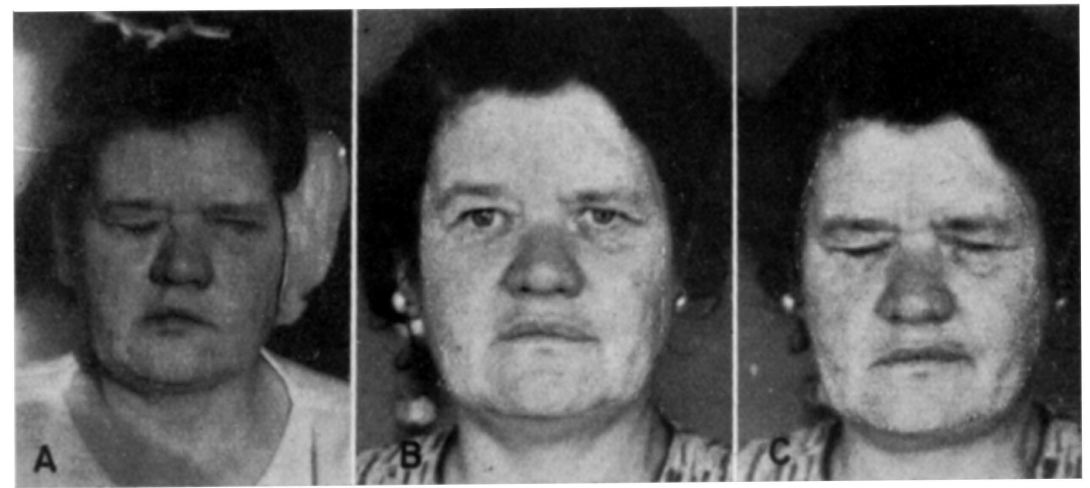

Fig. 37 - Nerve suture after re-routing the nerve according to Bunnell. Before $(A)$ and 2 years after the operation $(B, C)$.
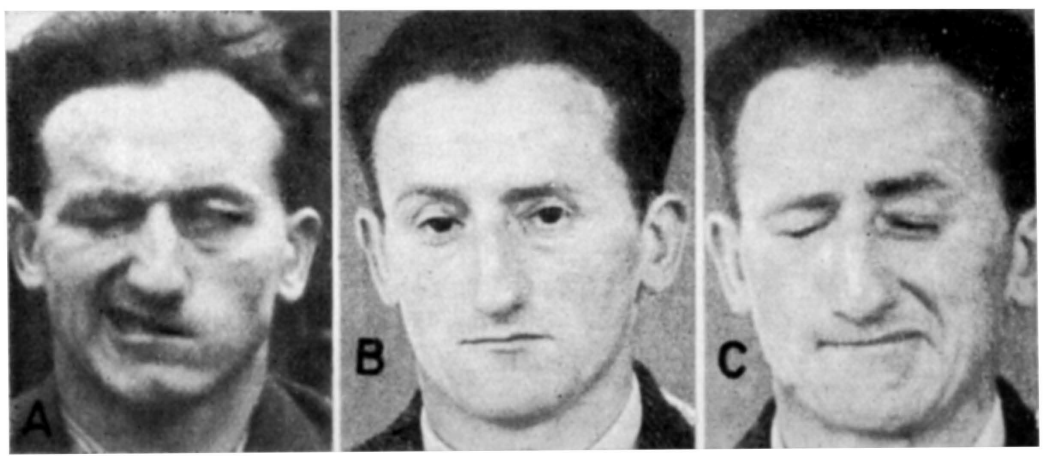

Fig. 38 - Nerve suture after re-routing the nerve according to Bunnell. Before (A) and 2 years after the operation $(B, C)$. 

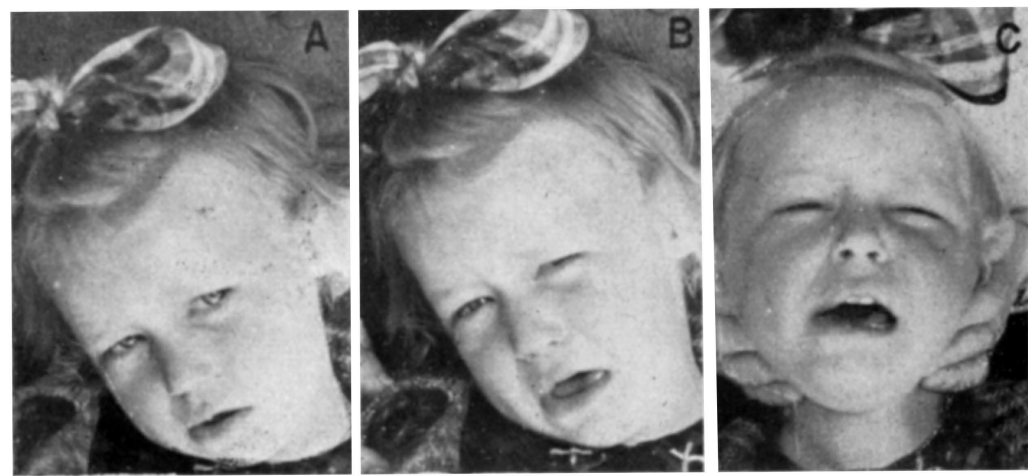

Fig. 39 - Approximatio n. facialis dextrus. During a simple mastoidectomy the nerve suffered a clear cut in the Fallopian canal as indicated. It was repaired a few days later, and is the only case where the stumps could be brought into contact after only limited mobilization. Pictures taken $11 / 4$ years after; stedily improving.
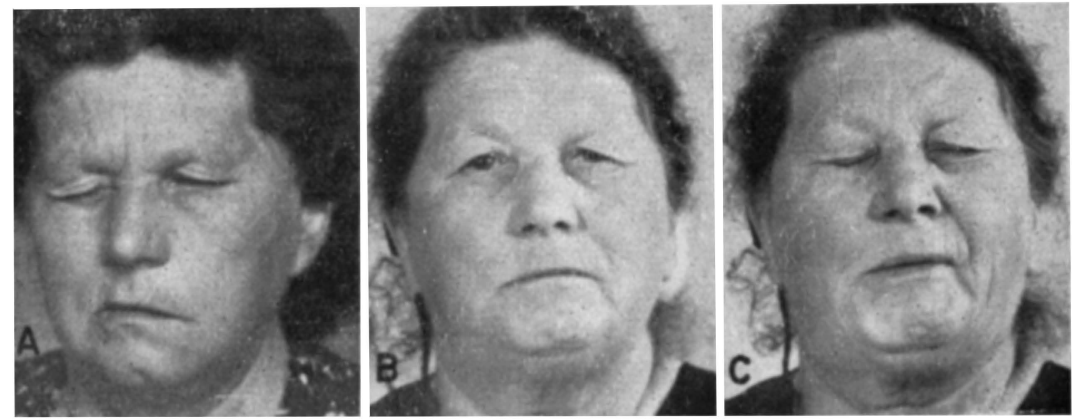

Fig. 40 - Re-routing of the nerve according to Bunnell. Approximation of the nerve stumps, which were glued together. Before (A) and $23 / 4$ years after the operation (B, C).

\section{BIBLIOGRAPHY}

1 Adans, W. M. - The use of the masseter, temporalis and frontalis muscles in the correction of facial paralysis. Plast. a. Reconst. Surg., 1, no. 2 (September) 1946. 2. Ballance, C.; Duel, A. B. - The operative treatment of facial palsy. Arch. Otolaryng., 15:1-70 (January) 1932. 3. Bauer, G. - Nerve graft in facial palsy. Acta Chir. Scandinav., 81:130, 1938. 4. Behrman, W. - The surgical treatment of peripheral facial paralysis in fractures of the cranial base. Acta Otolaryng., 37:187-190, 1949. 5. Bergström, E. - Good result after operation tor traumatic defect of the facial nerve. Hygiea, 8:2102, 1940. 6. Blair, V. P. Further observations upon the compensatory use of live tendon strips for facial 
paralysis. Ann. Sury., 92:694, 1930. 7. Bloch, A.; Bourgeois, R.; Aboulker, P. Lefèvre, J. - Le traitement chirurgical des paralysies faciales otologiques. Congrès de la Société Française d'Oto-Rhino-Laryngologie, 1950. 8. Brooke - A case of facial paralysis treated by facial grafts. Brit. J. Surg., 20:523, 1933. 9. Brown, J. B. - The utilization of the temporal muscle and fascia in facial paralysis. Ann. Surg., 109, no. 6 (June) 1939. 10. Brown, J. B.; McDowell, F.; Fryer, M. P. - Facial paralysis supported with autogenous fascia lata. Ann. Surgery, 127, no. 5 (May) 1948. 11. Brunner, H. - Treatment of inveterate facial paralysis. Plast. \& Reconstr. Surg., 8:390 (November) 1951. 12. Bunnell, S. - a) Suture of the facial nerve within the temporal bone. Surg., Gynec. a. Obst., !ng. 7-12 (July) 1927; b) Surgical repair of the facial nerve. Arch. Otolaryng., 25: 235-259, 1937; c) Summation of papers on management of facial paralysis. Arch. Otolaryng., 55:417 (April) 1952. 13. Bunnell, S.; Boyes, J. H. - Nerve grafts. Am. J. Surg., 44:64, 1939. 14. Cardwell, E. P. - Direct implantation of free nerve grafts between facial musculature and facial trunk. Arch. Otolaryng., 27: 469-472 (April) 1938. 15. Cawthorne, T. - a) Peripheral facial paralysis. Some aspects of its pathology. Laryngoscope, 56:653-664 (November) 1946; $b$ ) The pathology and surgical treatment of Bell's palsy. Paper read at the Fourth International Congress of Neurology, Paris, 1949; c) Bell's palsy. Lancet, no. 6683, pg. 593 (September 29) 1951; $a^{r}$ ) The rôle of surgery in the investigation and treatment of peripheral facial palsy. Lancet, pg. 1219 (June 21) 1952. 16. Collier, D. J. - a) Discussion on the limitations of operative treatment in traumatic facial paralysis. Proc. Roy. Soc. Med., 34 (March 7) 1941; b) The present position of facial nerve surgery. $\Lambda \mathrm{nn}$. Otol., Rhin. a. Laryng., 58:686 (September) 1949; c) 'The treatment of facial paralysis. Proc. Roy. Soc. Med., 43:746, 1950. 17. Duel, A. B. - History and development of the surgical treatment of facial palsy. Surg., Gynec. a. Obst., 56:382, 1933. 18. Duel, A. B.; 'Tickle, T. G. - The surgical repair of facial nerve paralysis. Ann. Otol., Rhin. a. Laryng., 45:3, 1936.19. Farrior, J. B.; Caldwell, P. C. - Facial nerve paralysis resulting from fracture of the temporal bone; report of a case. New Orleans M. a. S. J., 100:23-26 (July) 1947. 20. Findlay, J. P. - Facial paralysis. Angus \& Robertson Ltd., 89 Castlereagh St., Sydney, 1950. 21. Flodgren, E. - Contribution to the surgery of the facial palsy. Acta Oto-laryng., suppl. 74, pg. 188, 1948 22. Fogh-Andersen, P. Plastikkirurgisk behandling af invetereret facialisparese. Ugeskr. f. Laeger, 113: 828, 1948. 23. Fowler Jr., E. P. - The management and treatment of afflictions of the facial nerve within the fallopian canal. Acta Otolaryng., 27:615, 1939. 24. Kettel, K. - a) Neurinoma of the facial nerve. Arch. Otolaryng., 44:253, 1946; b) Nerve grafting and nerve suture in post-operative facial palsies. Proc. of the Fourth International Congress of Otolaryngology, London, 1949, vol. 1; c) Intratemporal sarcoma of the facial nerve. A rch. Otolaryng., 52:778 (November) 1950; d) Facial palsy of otitic origin. Arch. Otolaryng., 37:303-348, 1943; e) Prognosen for nervesutur og nervetransplantation ved perifer traumatisk facialisparese. Nord. Med., 43:1066, 1950; $f$ ) The prognosis of nerve grafting and nerve suture in peripheral facial palsies. Acta Otolaryng., suppl. 74, pg. 180, 1948. 25. Kisch, H. - Facial paralysis; Ballance-Duel nerve graft; recovery. Proc. Roy. Soc. Med., 29:1679, 1936. 26. Lathrop, F. D. - a) Facial nerve surgery in the European theater of operations. Laryngoscope, 56:665-676 (November) 1946; b) The practical anatomical and surgical considerations for exposure of the facial nerve. Laryngoscope, 58:743-760 (August) 1948; c) Affections of the facial nerve. Bull. New York Acad. Med., 28:796-808, 1952; d) The facial nerve: technique of exposure and repair. S. Clin. North America, 33, no. 3 (June) 1953; e) Affections of the facial nerve. J.A.M.A., 152:19-25 (May 2) 1953. 27. Lindsay, J. R. - Transplantation of facial nerve. Arch. Otolaryng., 27:131 (January) 1938. 28. Love, J. G.; Cannon, B. W. - Nerve anastomosis in the treatment of facial paralysis: special consideration of the etiologic rôle of total removal of tumors of the acoustic nerve. Arch. Surg., 62:379 (March) 1951. 29. Martin, R. C. -- a) Intratemporal suture of the facial nerve. Arch. Otolaryng., 13:259 (February) 1931; b) Surgical 
repair of the facial nerve. Arch. Otolaryng., 23:458 (April) 1936; c) Recent experiences with operation on facial nerve. Arch. Otolaryng., 32:1071 (December) $1940 ;$ d) Prognosis in traumatic peripheral facial paralysis. Laryngoscope, 61: 1004 (October) 1951; e) Bell's palsy. Arch. Otolaryng., 55, no. 4 (April) 1952. 30. Maxwell, J. H. - Extratemporal repair of the facial nerve. Case reports. Ann. Otol., Rhin. a. Laryng., 60:1114 (December) 1951. 31. McGillicuddy, O. B. - Facial nerve paralyses of twenty years' duration. Arch. Otolaryng., 58:310, 1953. 32. McArthur, G. A. D. -- Repair of facial nerve lesion by nerve graft. M. J. Australia, 2:1123, 1939. 33. Morris, W. M. - a) Surgical treatment of facial paralysis: a review of forty-six cases. Lancet, $2: 558,1939 ; b$ ) surgical treatment of Bell's palsy. Lancet, 1:429, 1938; $c$ ) Surgical treatrient of facial paralysis. Lancet, $2: 558,1939 ; d)$ Surgical treatment of facial paralysis. Lancet, 2: 1172, 1936. 34. Ney, K. W. - Facial paralysis and the surgical repair of the facial nerve. Laryngoscope, 32:327, 1922. 35. Owens, N. - a) Implantation of fascial strins through the masseter muscle for surgical correction of facial paralysis. Plast. a. Reconstr. Surgery, 2, no. 1 (January) 1947; b) Reevaluation of the implantation of fascial strips through the masseter muscle for surgical correction of facial paralysis. Ann. Otol., Rhin. a. Laryng., 57:55 (March) 1948. 36. Scott, S. - Nerve-graft in the treatment of facial paralysis: Ballance and Duel method. Proc. Roy. Soc. Med., 28:236, 1935. 37. Sullivin, J. -- a) Facial nerveplasna glue. Private communication; b) Modern Practice in Diseases of the Ear, Nose and Throat, vol. 2, section 1: Ear. Chapter 8: Injuries to ear (middle and inner); c) Recent advances in the surgical treatment of facial paralysis and Bell's palsy. Laryngoscope, 62:449 (May) 1952. 38. Tickle, T. G. -- a) The surgical treatment of facial paralyses. In Kopetzky, S. - Surgery of the Ear. Thomas Nelson \& Sons, New York, 1939; b) The surgical treatment of facial paralysis. Loose Leaf Surgery of the Ear. Chapter 14, pages 355-365, 1938; c) Surgery of the facial nerve in 300 operated cases. Laryngoscope, 55:191-195 (May) 1945; d) surgery of the seventh nerve. J.A.M.A., 136:969-972, 1948. 